\title{
Influence of moral intelligence, principled leadership and trust on organisational citizenship behaviour
}

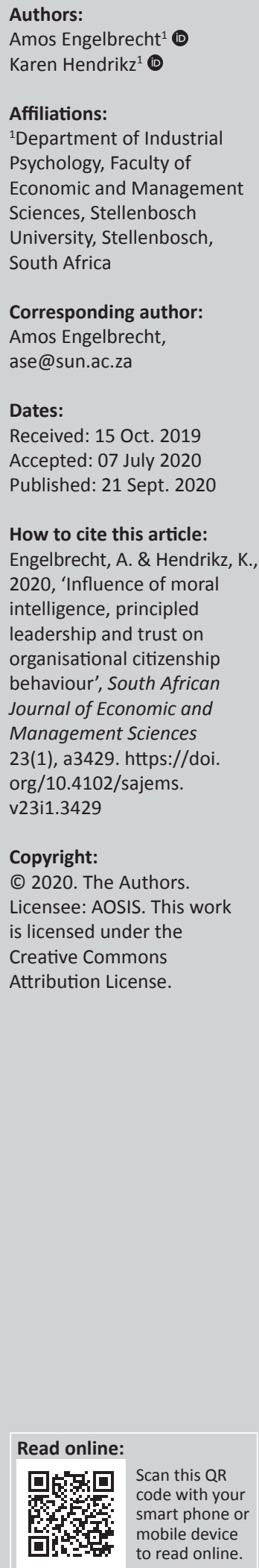

Background: Organisational citizenship behaviour (OCB) plays a substantial role in individual and organisational performance.

Aim: The aim of the study was to investigate how moral intelligence and principled leadership can influence trust in the leader and OCB.

Setting: Data were collected from 300 employees from various organisations in South Africa. Purposive, non-probability sampling was used.

Methods: A theoretical model and hypotheses were developed to explain the structural relationships among the latent variables. Data were analysed by means of item analysis and confirmatory factor analysis conducted via structural equation modelling (SEM).

Results: High levels of reliability were found for the measurement scales. Good model fit was demonstrated for the measurement and structural models. Empirical support was found for the significant mediating effects of principled leadership and trust in leaders in the indirect relationship between moral intelligence and OCB. The Principled Leadership Scale (PLS) could be used in the selection or development of principled leaders to develop an ethical culture to combat the high levels of corruption that many organisations face. Principled leaders play a key role in creating an ethical and trusting work climate conducive for OCB.

Conclusion: This study is the first to analyse the joint relationships among the specific latent variables in the structural model. Furthermore, the study provided the first supporting evidence for the concurrent validity of the newly developed PLS.

Keywords: ethical leadership; moral intelligence; principled leadership; leader trust; organisational citizenship behaviour.

\section{Introduction}

Several benefits of organisational citizenship behaviour (OCB) to organisations and employees have been cited in the literature, including: an increase in organisational efficiency and productivity through the freeing up and more effective allocation of human resources, better job performance in that colleagues and managers are more efficient at planning, scheduling and problem solving, higher quality of service delivery through positive employee attitudes, higher job satisfaction and organisational commitment, and retention of high-quality people because organisations gain a reputation for being good places to work at (Luthans 2011; Newman et al. 2014; Zhu et al. 2013).

Understanding how OCB can be fostered in organisations is thus clearly advantageous and important. The literature provides evidence that trust in the leader is a key antecedent to OCB (Chen et al. 2008; Dirks \& Ferrin 2002; Engelbrecht \& Chamberlain 2005; Newman et al. 2014). When followers perceive their leader to be trustworthy, they will be willing to voluntarily take on extra-role responsibilities.

Various prior studies provide evidence of a positive relationship between trust in the leader and value-based leadership, such as transformational (Dirks \& Ferrin 2002; Hemsworth, Muterera \& Baregheh 2013), authentic (Hassan \& Ahmed 2011; Walumbwa et al. 2008), servant (Joseph \& Winston 2005; Miao et al. 2014; Sendjaya \& Pekerti 2010) and ethical leadership (Engelbrecht, Heine \& Mahembe 2017; Lu 2014; Newman et al. 2014). Value-based leaders build mutual trust with their followers by displaying compassion, openness, integrity, empathy, fairness and moral role modelling. Furthermore, when leaders extend trust to followers, mutual trust is developed through social exchange mechanisms (Liden et al. 2014). 
Value-based leader behaviour is driven by integrity and well-developed moral intelligence (Beheshtifar Esmaeli \& Moghadam 2011; Engelbrecht, Kemp \& Mahembe 2018; Wickham \& O'Donohue 2012). The greater the moral intelligence of leaders, the more successful they will be at moral and ethical decision-making.

\section{Aim of the study}

In context of the above, the problem to be investigated in this study was: What are the key antecedents of OCB? The aim of the study then was to explore OCB as an asset to organisations, and to establish what the antecedents of OCB might be. Trust in leaders, value-based (principled) leadership and moral intelligence were proposed as such antecedents. Furthermore, the researchers sought to validate their assumptions through structural equation modelling (SEM) within a structural model of the relationships among these latent variables. The purpose of the study was thus to clarify strategies for the enhancement of OCB.

\section{Theoretical background and hypotheses \\ Organisational citizenship behaviour}

Organisational citizenship behaviour has been defined as 'individual behaviour that is discretionary, not directly or explicitly recognised by the formal reward system, and that in the aggregate promotes the effective functioning of the organisation' (Organ, Podsakoff \& MacKenzie 2006). OCB can be described as discretionary, contextual or extra-role performance (Asgari et al. 2008). According to Organ et al. (2006), OCB consists of five dimensions, namely: (1) altruism (e.g. providing voluntary assistance to other employees with a heavy workload), (2) courtesy (e.g. displaying behaviour that maintains good work relationships such as empathy and understanding, even when provoked), (3) civic virtue (e.g. taking part in volunteer projects that promote the good reputation of the organisation), (4) sportsmanship (e.g. not complaining about little inconveniences in the workplace) and (5) conscientiousness (e.g. working late to finish a project even though there is no direct financial reward).

\section{Trust in the leader and organisational citizenship behaviour}

As relational constructs, trust and OCB play a critical role in the social exchange context (Engelbrecht \& Chamberlain 2005; Rubin, Bommer \& Bachrach 2010). In a trust relationship, parties to the relationship are prepared to be vulnerable to one another's actions because of the expectation that when either party acts in a way that influences the other, the rights and interests of the other will not be violated (Hassan \& Ahmed 2011; Joseph \& Winston 2005).

Trusting the leader to not violate the rights and interests of the follower is important because leaders are in a position where they make decisions and take actions, which directly affect followers. Trust is established through inferences that followers make about the nature of their relationship with the leader, based on the actions and character of the leader (Dirks \& Ferrin 2002). Mutual trust develops over time as employees and their leader engage in the exchange of socioemotional benefits through the display of concern, respect and care for each other (Zhu et al. 2013). This should in turn strengthen the emotional bond between followers and their leader.

When followers perceive their leader to be capable, benevolent and to have integrity, they will be more willing to reciprocate with desirable behaviours like OCB (Dirks \& Ferrin 2002; Organ et al. 2006; Rubin et al. 2010; Zhu et al. 2013). A trusting relationship between employees and their leader should also enhance group cohesion, which can lead to a greater willingness of employees to go above and beyond their job role to help others and support their organisation on a voluntary basis (Zhu et al. 2013). In contrast, when the leader is perceived to be untrustworthy, followers will divert energy to protecting themselves, instead of focussing on their work performance (Dirks \& Ferrin 2002).

Several researchers have found a positive relationship between trust in leadership and OCB (Asgari et al. 2008; Chen et al. 2008; Dirks \& Ferris 2002; Engelbrecht \& Chamberlain 2005; Newman et al. 2014; Rubin et al. 2010; Shahzad et al. 2013). Employees are more likely to demonstrate OCB when they trust their leader and when they experience an exchange of socio-emotional benefits in their relationship with the leader. This leads to the formulation of the first research hypothesis:

H1: Trust in the leader has a significant, positive influence on OCB.

\section{Value-based leadership as an antecedent of trust}

If the trust relationship between leader and follower is dependent largely on the character and actions of the leader, what character and actions should a leader display to foster the trust relationship? From the above it would seem that behaviours such as trustworthiness, integrity, benevolence, compassion and honesty are important.

These types of behaviours are typical of what the researchers have grouped as value-based leader behaviours, that is, leader behaviours that are based on the 'golden rule' of do unto others as you would have them do unto you (Kinnier, Kernes \& Dautheribes 2000; Lennick \& Kiel 2008). When examining the most prominent leadership theories, those that align most closely to these behaviours are transformational, servant, authentic and ethical leadership. Ample studies have been conducted that provide proof of the positive relationship between each of these theories and trust in the leader.

Transformational leaders were found to build trust through individualised concern for followers, which led to care for and development of the follower and strong emotional bonds 
between follower and leader (Asgari et al. 2008; Dirks \& Ferrin 2002; Hemsworth et al. 2013; Zhu et al. 2013).

Relational transparency and self-awareness were found to be key ingredients to building trust between authentic leaders and their followers. Relational transparency leads to openness and the expression of true thoughts and feelings about issues and a forthrightness of communication, while self-awareness leads the leader to be honest about their strengths and weaknesses and how these affect others (Hassan \& Ahmed 2011; Joseph \& Winston 2005; Walumbwa et al. 2008).

Servant leaders build trust through their insight, empathy, concern for the welfare of their followers, as well as the ethical example they set for followers (Joseph \& Winston 2005; Miao et al. 2014; Sendjaya \& Pekerti 2010).

Ethical leaders seem to enhance mutual trust by behaviour that is typically marked by the care, equity, fairness and respect they show towards their followers (Engelbrecht et al. 2017; Hassan \& Ahmed 2011; Hemsworth et al. 2013; Keck et al. 2018; Miao et al. 2014; Newman et al. 2014; Sendjaya \& Pekerti 2010; Zhu et al. 2013).

\section{Principled leadership and trust}

In analysing the behaviours of value-based leaders, the researchers found that there was a great deal of overlap in the behaviours inherent to the four value-based leadership theories mentioned above. While each placed an emphasis on specific moral values, they all essentially measure moral leadership (Xu, Caldwell \& Anderson 2016). To measure the underlying behaviours of transformational, servant, authentic and ethical leadership, Hendrikz and Engelbrecht (2019) developed principled leadership as a holistic, valuebased leadership construct, defining principled leadership as follows:

Principled leaders inspire and motivate others with a sense of purpose that goes beyond their own needs and desires; they are trustworthy and act as role models of universally accepted moral behaviour, by mastering their behaviour and interactions with others through humility, openness and vulnerability, by focussing on the empowerment of others and by taking accountability for their own actions and holding others to account for theirs.

Trust is an essential component of the social exchange theory (Sendjaya \& Pekerti 2010). Social exchange is the voluntary actions of employees who are motivated by an expectation of support and benefits from their leader (Blau 1964). Principled leaders may thus influence follower trust in leaders through social exchange. Furthermore, principled leaders may gain follower trust through role modelling, a phenomenon that can be understood using social learning theory (Brown \& Treviño 2006). According to this theory, individuals learn by observing the behaviour of role models chosen, based on their attractiveness and credibility. Principled leaders are particularly likely to become role models, because their behaviours, specifically integrity, concern for others and strong ethics, may enhance their attractiveness and trustworthiness, resulting in greater credibility (Brown \& Treviño 2006; Liden et al. 2014; Walumbwa et al. 2008). Such leadership behaviours provide a psychologically secure environment in which employees can develop high levels of trust in the leader (Lu 2014). Consequently, the following hypothesis can be postulated:

H2: Principled leader behaviour has a significant, positive influence on trust in the leader.

\section{Moral intelligence as an antecedent of principled leadership}

The discussion to this point has highlighted several behaviours that would be expected from principled leaders. However, not all leaders behave in a principled manner. The Enron debacle of 2001 and more recently the scandals involving Volkswagen, FIFA, Steinhoff, Bosasa and the alleged state capture of the South African government indicate that immoral leader behaviour is alive and well. A question that begs answering in this regard is why some people are more inclined to act morally than others?

To explore this question, the researchers investigated the concept of moral intelligence, which has been defined as follows: 'Moral intelligence is the mental capacity to determine how universal human principles should be applied to our values, goals and actions' (Lennick \& Kiel 2008:7). The understanding of moral intelligence requires a brief discussion of research relating to the origins of morality.

\section{The origins of moral intelligence}

In Plato's opinion, the development of the ability to reason brought about morality, which in turn controlled the wayward emotions of humankind (Narvaez 2010). Plato's pupil, Aristotle, alleged that humans possess within themselves the emotional and rational abilities necessary to achieve moral excellence, which can be developed through proper guidance by society and family (Dow 1998).

The theologian Augustine argued that, essentially, man desires happiness and peace. However, when his will is directed towards selfish desires instead of towards God, he will act immorally (Wogaman 2011). To counteract this inherent selfishness, morality must be developed through training of good habits (Narvaez 2010).

Similarly, Confucius in China, and Buddha in India, held the view that people within themselves want to be just, selfcontrolled, and temperate as this is critical for their wellbeing and happiness (Hass 1998).

In addition to the philosophical viewpoints stated above, empirical science has begun to prove that an innate propensity to be moral is part of the physical make-up of all human beings (Lennick \& Kiel 2008; Narvaez 2010). As suggested by the ancient philosophers and modern psychology, nurturing, 
training and development of this inborn morality is, however, necessary for humans to function effectively in terms of their morality (Lennick \& Kiel 2008).

\section{Benefits of moral intelligence for leadership}

The most defining benefit of moral intelligence is that it is viewed as the 'central intelligence', which provides an anchor for the cognitive, emotional and social intelligences, ensuring that the right thing is done, rather than acting in possible destructive ways (Beheshtifar et al. 2011; Lennick \& Kiel 2008).

Liden et al. (2014) analysed moral maturity and moral conation, which are related concepts to moral intelligence. Leaders who possess moral maturity are likely to behave in a way that is consistent with their personal ethical norms (i.e., their moral identity). Moral conation is the capacity to believe one is morally responsible and act in a moral way, even in the face of obstacles. Liden et al. (2014) view moral maturity and moral conation as antecedents of the ethical behaviours of servant leaders. Furthermore, leaders' cognitive moral development has been found to be positively linked to ethical decision-making (Ashkanasy, Windsor \& Treviño 2006).

In today's world of work, leaders will inevitably be faced with ethical decisions and the more adept they are at handling these, the more successful they will be (Beheshtifar et al. 2011; Liden et al. 2014). Morally intelligent leaders thus have an edge on those who have an underdeveloped inner moral compass (Beheshtifar et al. 2011; Engelbrecht et al. 2018). This led to the postulation of the following hypothesis:

H3: Moral intelligence has a significant, positive influence on principled leader behaviour.

\section{Conceptual model}

Based on the analysis of the above-mentioned literature a conceptual model of the relationships among moral intelligence, principled leadership, trust in the leader and OCB was developed (see Figure 1).

\section{Research method}

\section{Sample selection and data collection}

Purposive, non-probability sampling was used to select participants from various companies in South Africa. The participating organisations included software development and consulting services (80\%), retail (6\%), wine making (5\%), construction $(5 \%)$ and public service $(4 \%)$. The population can be defined as middle to top management in organisations. The sample of 300 respondents consisted of employees who reported to managers in such positions. Of the respondents, $58 \%$ were working in non-managerial positions, 31\% in lower to mid-level management and $11 \%$ in senior to top management level positions. The average age of participants was 33 years.

Electronic or paper-based questionnaires were sent either to a contact person at the organisation for further distribution, or directly to participants. In the covering letter, the purpose of the research was clearly explained to participants; confidentiality and anonymity were guaranteed and feedback would be provided in aggregate format only. Furthermore, electronic data was directly sent to the statistical centre of the university.

\section{Measuring instruments}

The researchers utilised the following scales to measure the four components of the structural model:

\section{Moral intelligence}

The Moral Competency Inventory (MCI) measures the four moral intelligence principles of integrity, responsibility, compassion and forgiveness (Lennick \& Kiel 2008). An adapted 29-item MCI (AMCI) was used to measure moral intelligence in this study.

Research participants were required to evaluate the moral intelligence of their line manager. This required the researchers to change the original self-rating scale to an other-rating scale. In doing so, it was necessary to remove 11 items, as it would not be possible for a subordinate to rate the extent to which their manager displays these behaviours (i.e., items 2, 9, 10, 11, 19, 20, 29, 30, 31, 39 and 40). The removed items primarily refer to the principle of forgiveness.

\section{Principled leadership}

The new 58-item Principled Leadership Scale (PLS) developed by Hendrikz and Engelbrecht (2019) was utilised to measure principled leadership. Four subscales were developed for the PLS, namely trustworthiness, self-mastery, empowerment and accountability. Participants rated the principled behaviour of their line manager.

\section{Trust in the leader}

Trust in the leader was measured using the 13-item Leader Trust Scale (LTS) developed by Engelbrecht et al. (2017). Participants assessed the level of trust they had in their line manager.

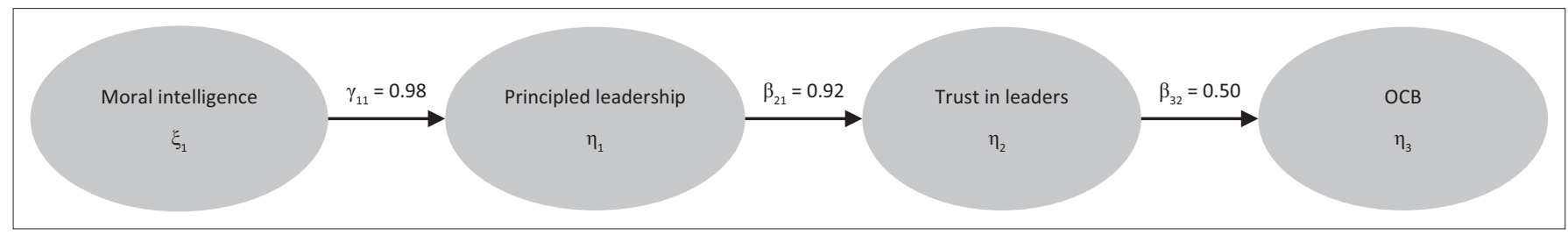

$O C B$, organisational citizenship behaviour.

FIGURE 1: Relationships among moral intelligence, principled leadership, trust and organisational citizenship behaviour. 
The item analysis of the LTS achieved a good Cronbach's alpha value $(\alpha=0.97)$ (Engelbrecht et al. 2017; Nunnally 1978). A confirmatory factor analysis showed close fit $(p>0.05)$ of the LTS measurement model with the empirical data $(\mathrm{RMSEA}=0.067$; standardised root mean residual $[\mathrm{SRMR}]=0.03$; normed fit index $[\mathrm{NFI}]=0.98)($ Engelbrecht et al. 2017).

\section{Organisational citizenship behaviour}

Organisational citizenship behaviour was measured using Engelbrecht and Chamberlain's (2005) modification of Podsakoff and MacKenzie's 24-item Organisational Citizenship Behaviour Scale (OCBS). This modified scale allows for self-reporting and ensures that the wording of questions is relevant for the South African context (Engelbrecht \& Chamberlain 2005). Research participants evaluated their own organisational citizenship behaviour.

The adapted OCBS achieved an acceptable level of internal consistency for the total scale $(\alpha=0.78)$ (Engelbrecht \& Chamberlain 2005).

\section{Ethical consideration}

The Research Ethics Committee of Stellenbosch University granted ethical clearance for the study: SU-HSD-000617. Furthermore, informed consent was sought from participating employers and respondents.

\section{Results}

\section{Descriptive statistics and reliability analysis}

Table 1 presents the means, standard deviations, reliability coefficients ( $\alpha$ values) and Pearson correlation coefficients for all four measures included in the study.
Reliability analysis was also conducted on each of the dimensions of the scales comprising the structural model. All the Cronbach's alpha values were above the acceptable cutoff value of 0.70 (Nunnally 1978) except for the subscale Civic Virtue of the OCBS, for which a value of 0.66 was obtained. As per Nunnally (1978) this deems the dimension to have low but acceptable reliability. In addition, the corrected itemtotal correlations were satisfactory $(>0.30)$ for all subscales (Pallant 2013) (see Table 2).

\section{Evaluation of the fit of the measurement models}

The fit of the measurement models was investigated by performing confirmatory factor analysis (CFA) to determine whether the theorised models were supported by the data collected.

\section{Adapted Moral Competency Inventory}

The AMCI measurement model achieved a reasonable fit with the data indicated by the RMSEA and SRMR indices (see Table 3). However, the goodness-of-fit (GFI) showed poor fit and the index of close fit $(p<0.05)$ did not support the close fit hypothesis. The NFI and comparative fit index (CFI) values indicated good fit (Hooper, Coughlan \& Mullen 2008). Furthermore, the factor loadings of the items on their dimensions were significant and greater than the desired 0.50 (MacKenzie, Podsakoff \& Podsakoff 2011), ranging from 0.63 to 0.87 . On balance, the measurement model of the AMCI was regarded as showing reasonable fit.

\section{Principled Leadership Scale}

A confirmatory bi-factor analysis provided close fit $(p>0.05)$ of the PLS measurement model with the empirical data (Hendrikz \& Engelbrecht 2019) (see Table 3). The GFI produced a poor model fit $(<0.90)$, but the RMSEA, SRMR

TABLE 1: Descriptive statistics and Pearson correlations $(N=300)$.

\begin{tabular}{|c|c|c|c|c|c|c|}
\hline Measures & Mean & Standard deviation & 1 & 2 & 3 & 4 \\
\hline 1. Moral Intelligence & 115.85 & 19.32 & (0.98) & - & - & - \\
\hline 2. Principled Leadership & 230.61 & 36.41 & $0.95^{*}$ & (0.98) & - & - \\
\hline 3. Trust in leaders & 54.44 & 9.12 & $0.92 *$ & $0.90 *$ & $(0.97)$ & - \\
\hline 4. Organisational citizenship behaviour & 98.00 & 9.00 & $0.38 *$ & $0.40 *$ & $0.41 *$ & $(0.79)$ \\
\hline
\end{tabular}

Note: Cronbach's $a$ values for the measures are shown in parentheses along the diagonal.

$*, p<0.01$.

TABLE 2: Reliability results of the four scales.

\begin{tabular}{|c|c|c|c|c|}
\hline Scale & Dimension & Number of items & Cronbach's alpha & Item-total correlation range \\
\hline \multirow[t]{3}{*}{ Adapted Moral Competency Inventory } & Responsibility & 12 & 0.956 & $0.695-0.847$ \\
\hline & Integrity & 13 & 0.932 & $0.439-0.769$ \\
\hline & Compassion & 4 & 0.748 & $0.409-0.610$ \\
\hline \multirow[t]{4}{*}{ Principled Leadership Scale } & Trustworthiness & 16 & 0.951 & $0.592-0.842$ \\
\hline & Self-mastery & 17 & 0.957 & $0.609-0.811$ \\
\hline & Empowerment & 13 & 0.933 & $0.435-0.817$ \\
\hline & Accountability & 12 & 0.892 & $0.500-0.692$ \\
\hline Leader Trust Scale & - & 13 & 0.966 & $0.709-0.870$ \\
\hline \multirow[t]{5}{*}{ Organisational Citizenship Behavioural Scale } & Altruism & 5 & 0.782 & $0.475-0.612$ \\
\hline & Conscientiousness & 5 & 0.705 & $0.386-0.516$ \\
\hline & Sportsmanship & 5 & 0.762 & $0.438-0.659$ \\
\hline & Civic virtue & 4 & 0.659 & $0.364-0.518$ \\
\hline & Courtesy & 5 & 0.742 & $0.382-0.604$ \\
\hline
\end{tabular}


TABLE 3: Goodness-of-fit indices.

\begin{tabular}{|c|c|c|c|c|c|c|c|c|}
\hline MODEL & $\mathrm{S}-\mathrm{B} \chi^{2}$ & $d f$ & RMSEA & Pclose fit & SRMR & GFI & NFI & $\mathrm{CFI}$ \\
\hline $\mathrm{AMCl}$ & $1465.04 *$ & 374 & 0.075 & 0.000 & 0.052 & 0.732 & 0.975 & 0.984 \\
\hline PLS & $2576.33^{*}$ & 1531 & 0.048 & 0.872 & 0.040 & 0.727 & 0.979 & 0.992 \\
\hline LTS & $106.56 *$ & 65 & 0.046 & 0.636 & 0.027 & 0.897 & 0.991 & 0.996 \\
\hline OCBS & $329.45 *$ & 242 & 0.035 & 0.998 & 0.052 & 0.904 & 0.936 & 0.982 \\
\hline MEAS & $256.19 *$ & 183 & 0.037 & 0.987 & 0.022 & 0.915 & 0.991 & 0.997 \\
\hline STRUCT & 293.38* & 186 & 0.044 & 0.851 & 0.023 & 0.904 & 0.989 & 0.996 \\
\hline
\end{tabular}

S-B $\chi^{2}$, Sattora-Bentler scaled chi-square; $d f$, degrees of freedom; RMSEA, root mean square error of approximation; Pclose fit, $p$-value for test of close fit (RMSEA < 0.05 ); SRMR, standardised root mean residual; GFI, Goodness-of-fit index; NFI, Normed fit index; CFI, comparative fit index; ACMI, Adapted Moral Competency Inventory; PLS, Principled Leadership Scale; LTS, Leader Trust Scale; OCBS, OCB Scale; MEAS, overall measurement model; STRUCT, structural model.

$*, p<0.05$.

and relative fit indices indicated good model fit (Hooper et al. 2008). Overall, the bi-factor measurement model showed good fit.

\section{Leader Trust Scale}

Good fit was indicated by all fit indices except the GFI, which narrowly missed the 0.90 cut-off point (see Table 3 ). The $p$-value for close fit $(>0.05)$ also supported the close fit hypothesis. In addition, all the factor loadings in the completely standardised LAMBDA-X matrix were significant and greater than 0.50 (MacKenzie et al. 2011), ranging from 0.72 to 0.89 . Overall, the researchers deemed the LTS to have good fit.

\section{Organisational Citizenship Behavioural Scale}

The OCBS's $p$-value for close fit met the criterion necessary to support the close fit hypothesis (see Table 3). The SRMR and NFI showed acceptable fit while the other fit indices indicating good fit. The factor loadings were above 0.50 (MacKenzie et al. 2011) for all items except for OCB6 and OCB17. The factor loading range for the remaining items was between 0.52 and 0.79 . In the unstandardised LAMBDA-X matrix, the $z$-value for both these items was however greater than $|1.64|$, indicating significant $(p<0.05)$ factor loadings ( $z=6.38$ for OCB6 and $z=7.28$ for OCB17). The researchers thus concluded that the measurement model for the OCBS showed good fit.

\section{Overall measurement model underlying the structural model}

All fit indices of the overall measurement model underlying the structural model indicated good fit. In addition, the $p$-value for close fit supported the close fit hypothesis (see Table 3).

\section{Structural model fit}

The structural model also showed good fit. This was supported by all the fit indices. Support was also found for the close fit hypothesis (see Table 3).

\section{Discussion of results}

Statistical analysis of the links between the variables of the structural model was necessary to determine whether the data supported the relationships between these variables, as originally conceptualised.

\section{The relationship between trust in the leader and organisational citizenship behaviour}

Hypothesis 1 postulated a positive relationship between trust in the leader $\left(\mathrm{y}_{2}\right)$ and OCB $\left(\mathrm{y}_{3}\right)$. This was confirmed by this study $(\beta=0.50 ; p<0.05)$ (see Table 4$)$. This corroborates the results of prior studies in which a positive, significant relationship between trust in leadership and OCB was found (Asgari et al. 2008; Chen et al. 2008; Engelbrecht \& Chamberlain 2005; Newman et al. 2014; Rubin et al. 2010; Shahzad et al. 2013). Thus, if employees believe their leaders to be highly trustworthy, they will in turn display greater levels of OCB.

\section{The relationship between principled leadership and trust in the leader}

The study supported Hypothesis 2, which proposed that a positive, significant relationship exists between principled leadership $\left(\mathrm{y}_{1}\right)$ and trust in the leader $\left(\mathrm{n}_{2}\right)(\beta=0.92 ; p<0.05)$ (see Table 4). This confirms prior findings of a positive relationship between value-based or principled leadership and trust in leaders (Engelbrecht et al. 2017; Hassan \& Ahmed 2011; Hemsworth et al. 2013; Keck et al. 2018; Miao et al. 2014; Newman et al. 2014; Sendjaya \& Pekerti 2010; Zhu et al. 2013). Principled leaders will therefore create high levels of trust between subordinates and their leaders.

\section{The relationship between moral intelligence and principled leadership}

Support was found for Hypothesis 3, which suggested that a positive, significant relationship exists between moral intelligence $\left(\xi_{1}\right)$ and principled leadership $\left(\mathrm{n}_{1}\right) \quad(\beta=0.98$; $p<0.05$ ) (see Table 4). This supports the positive relationship established between integrity, as well as cognitive moral development and value-based or principled leadership (Ashkanasy et al. 2006; Beheshtifar et al. 2011; Engelbrecht et al. 2018; Lennick \& Kiel 2008; Liden et al. 2014). Consequently, leaders with a high level of moral intelligence will exhibit strong principled leadership.

\section{The mediating effects of principled leadership and trust in the leader}

Based on the results of the direct relationships, two ad hoc analyses were conducted to test mediator effects formally. Firstly, the significance of the mediation effect of trust in the leader in the principled leadership-OCB relationship was 
TABLE 4: Gamma and beta matrix of the structural model's path coefficients.

\begin{tabular}{|c|c|c|c|c|c|c|c|c|c|}
\hline \multirow[t]{2}{*}{ Latent variable } & \multicolumn{3}{|c|}{ Moral intelligence } & \multicolumn{3}{|c|}{ Principled leadership } & \multicolumn{3}{|c|}{ Trust in leader } \\
\hline & Path coefficient & Standard error & $t$-value & Path coefficient & Standard error & $t$-value & Path coefficient & Standard error & $t$-value \\
\hline Principled leadership & $0.98 \dagger$ & 0.05 & $20.53 *$ & - & - & - & - & - & - \\
\hline Trust in leader & - & - & - & $0.92 \dagger$ & 0.04 & $26.40^{*}$ & - & - & - \\
\hline Organisational citizenship behaviour & - & - & - & - & - & - & $0.50 \dagger$ & 0.07 & $7.20 *$ \\
\hline
\end{tabular}

Note: $t$-values $\geq|1.64|$ indicate significant parameter estimates.

$*, p<0.05$.

$\dagger$, completely standardised path coefficients.

tested (as both Hypothesis 1, the effect of trust in the leader on OCB, and Hypothesis 2, the effect of principled leadership on trust in the leader, were supported). The results of the Sobel test (Preacher \& Hayes 2004) revealed that trust in the leader significantly mediated the relationship between principled leadership and OCB $(z=2.88 ; p<0.01)$. Secondly, as both Hypothesis 2 and Hypothesis 3 (the effect of moral intelligence on principled leadership) were supported, principled leadership as a mediator in the moral intelligence-trust in the leader relationship was formally tested. The results $(z=5.21$; $p<0.01)$ confirmed this mediation effect.

\section{Modification indices}

Analysis of the modification indices did not show any other significant, positive paths that could be considered within the structural model, other than those postulated as part of the study.

\section{Limitations of the study and suggestions for future research}

The study had certain limitations and revealed areas for future research, which should be considered. The study was based on self-report questionnaires. Common method bias stemming from data collection by means of self-report measures has been shown to inflate the strength of observed relationships (Williams \& McGonagle 2016). It would be useful if future research could replicate the findings in the current study by using approaches such as the Hybrid Method Variables Model to control for common method bias (Williams \& McGonagle 2016).

The four scales utilised in the study were related with their respective antecedents and outcomes as a whole, rather than by dimensions. It may be useful to know to which extent the dimensions of moral intelligence affect the separate dimensions of principled leadership, and which of the leadership dimensions bear most weight in affecting trust in the leader. This would assist with knowing which behaviours to focus on developing to positively influence OCB.

A more detailed study on the item and factor structure of the adapted MCI may increase the reliability of the third dimension, Compassion, as well as the fit of the measurement model. This study analysed the reliability and factor structure of the AMCI by loading the items onto three moral intelligence principles. The researchers suggest that further analysis of the MCI is conducted in a model where the items load on their related moral intelligence competencies, which in turn load on the four moral intelligence principles as postulated by Lennick and Kiel (2008).

This study provided preliminary evidence of the reliability and concurrent validity of the PLS within a nomological network of specific latent variables. Future studies should identify other correlates of principled leadership (e.g. organisational justice, empowerment, employee wellness, ethical climate, leader effectiveness) to further determine the construct validity of the PLS in a more elaborate structural model of principled leadership.

Finally, a longitudinal study would be valuable to substantiate the causal relationships postulated in the structural model.

\section{Managerial implications}

The aim of the study was to determine what precedes OCB in the work context. The literature and this study provided support for the hypothesis that trust in the leader has a positive influence on OCB. By implication, organisations should thus aim to increase the level of trust between managers and subordinates to increase OCB and ultimately positive organisational results such as job satisfaction, the ability to attract and maintain a good workforce, and greater efficiency and productivity (Luthans 2011; Newman et al. 2014; Zhu et al. 2013).

The study proves that principled leadership has a positive influence on trust in leaders. Principled managers can utilise various strategies that may enhance a social exchange relationship with their subordinates, which, in turn, will help develop managers' trustworthiness. These strategies might include empowering subordinates, benevolence and caring for subordinates, accountability, displaying a high consistency between moral intentions and actions, being selfaware and displaying authenticity in relationships (Dirks \& Ferrin 2002; Zhu et al. 2013). The strong links between principled leadership and trust in the leader in this study emphasise the importance of developing principled behaviour in managers to increase the level of trust between them and their subordinates.

Finally, the positive relationship between moral intelligence and principled leadership emphasises an important link between these two constructs. Lennick and Kiel (2008) argue that when managers have a high propensity to display behaviours linked to integrity, responsibility, compassion and forgiveness, they can be regarded as being morally 
intelligent. Moral intelligence in managers is important because it forms the moral compass, which directs the optimal utilisation of managers' other intelligences (e.g. emotional intelligence) (Beheshtifar et al. 2011).

The behaviours identified in moral intelligence are effectively a prerequisite to principled leader behaviour. Without the innate ability to behave with integrity, responsibility, compassion and forgiveness, managers will struggle to display behaviour aligned with universally accepted moral values and to stand their ground about what is ethical. It will be difficult for such a manager to take on the responsibility of devising a strategy that is focussed wider than the bottom line of profits, or to build an organisation that is financially sustainable in the long term, without using the planet or people as means to build that sustainability. Such managers will not have the service attitude necessary to be able to put the development needs of subordinates at the forefront of their responsibilities, nor will they have the necessary humility to question their thinking and be open to the ideas of others. Essentially, a manager who is not morally intelligent will also not be principled.

\section{Conclusion}

In conclusion, this study provides some evidence for the concurrent validity of the newly developed PLS through the positive mediating effect of trust in the leader on the indirect impact of principled leadership on OCB, as well as the positive mediating effect of principled leadership on the indirect influence of moral intelligence on trust in the leader. Moreover, this study promotes the argument that if employee behaviour, specifically $\mathrm{OCB}$, is an asset to an organisation, the leaders of the organisation should focus on developing their moral intelligence and principled behaviour to increase mutual trust and $\mathrm{OCB}$, and ultimately the organisational benefits brought about through OCB.

\section{Acknowledgements Competing interests}

The authors declare that they have no financial or personal relationships that may have inappropriately influenced them in writing this article.

\section{Authors' contributions}

Both A.E. and K.H. were responsible for the conceptualisation of the study, the interpretation of the findings and writing of the article. K.H. was also responsible for the data collection and statistical analyses.

\section{Funding information}

This research received no specific grant from any funding agency in the public, commercial, or not-for-profit sectors.

\section{Data availability statement}

Data supporting the findings of this study are available within the article.

\section{Disclaimer}

The views and opinions expressed in this article are those of the authors and do not necessarily reflect the official policy or position of any affiliated agency of the authors.

\section{References}

Asgari, A., Silong, A.D., Ahmad, A. \& Samah, B.A., 2008, 'The relationship between transformational leadership behaviors, organizational justice, leader-member exchange, perceived organizational support, trust in management and organizational citizenship behaviors', European Journal of Scientific Research 23(2), 227-242.

Ashkanasy, N.M., Windsor, C.A. \& Treviño, L.K., 2006, 'Bad apples in bad barrels revisited: Cognitive moral development, just world beliefs, rewards, and ethical decision-making', Business Ethics Quarterly 16, 449-473. https://doi.org/10.5840/ beq200616447

Beheshtifar, M., Esmaeli, Z. \& Moghadam, M.N., 2011, 'Effect of moral intelligence on leadership', European Journal of Economics, Finance and Administrative Services 43, 6-11.

Blau, P.M., 1964, Exchange and power in social life, Wiley, New York, NY

Brown, M.E. \& Trevino, L.K., 2006, 'Ethical leadership: A review and future directions', Leadership Quarterly 17(6), 595-616. https://doi.org/10.1016/j.leaqua.2006. 10.004

Chen, C.V., Wang, S., Chang, W. \& Hu, C., 2008, 'The effect of leader-member exchange, trust, supervisor support on organisational citizenship behavior in nurses', Journal of Nursing Research 16(4), 321-327. https://doi.org/10.1097/01. JNR.0000387319.28010.5e

Dirks, K.T. \& Ferrin, D.L., 2002, 'Trust in leadership: Meta-analytic findings and implications for research and practice', Journal of Applied Psychology 87(4), 611-628. https://doi.org/10.1037/0021-9010.87.4.611

Dow, L.R., 1998, 'Growing up happy: Aristotle's theory of moral education', Doctora thesis, University of Toronto, Ontario.

Engelbrecht, A.S. \& Chamberlain, L., 2005, 'The influence of transformational leadership on organisational citizenship behaviour through justice and trust' Management Dynamics 14(1), 2-12. https://doi.org/10.1108/LODJ-11-2015-0237

Engelbrecht, A.S., Heine, G. \& Mahembe, B., 2017, 'Integrity, ethical leadership, trust and work engagement', Leadership and Organization Development Journal 38(3), 368-379.

Engelbrecht, A.S., Kemp, J. \& Mahembe, B., 2018, 'The effect of altruism and integrity on ethical leadership and organisational justice', Management Dynamics 27(4), 1-11.

Hass, A., 1998, Doing the right thing, Pocket Books, New York, NY.

Hassan, A. \& Ahmed, F., 2011, 'Authentic leadership, trust and work engagement', International Journal of Human and Social Sciences 6(3), 164-170.

Hemsworth, D., Muterera, J. \& Baregheh, A., 2013, 'Examining Bass's transformational leadership in public sector executives: A psychometric properties review', The Journal of Applied Business Research 29(3), 853-862. https://doi.org/10.19030/ jabr.v29i3.7785

Hendrikz, K. \& Engelbrecht, A.S., 2019, 'The principled leadership scale: An integration of value-based leadership', SA Journal of Industrial Psychology 45(1), 1-10. https://doi.org/10.4102/sajip.v45i0.1553

Hooper, D., Coughlan, J. \& Mullen, M., 2008, 'Structural equation modelling: Guidelines for determining model fit', Journal of Business Research Methods $6(1), 53-60$

Joseph, E.E. \& Winston, B.E., 2005, 'A correlation of servant leadership, leader trust, and organisational trust', Leadership and Organisation Development Journa 26(1), 6-22. https://doi.org/10.1108/01437730510575552

Keck, N., Giessner, S.R., Van Quaquebeke, N. \& Kruijff E., 2018, 'When do followers perceive their leaders as ethical? A relational models perspective of normatively appropriate conduct', Journal of Business Ethics 153, 1-17.

Kinnier, R.T., Kernes, J.L \& Dautheribes, T.M., 2000, 'A short list of universal moral values', Counselling and Values 45, 4-6. https://doi.org/10.1002/j.2161-007X.2000. tb00178.x

Lennick, D. \& Kiel, F., 2008, Moral intelligence, Wharton School Publishing, Upper Saddle River, NJ.

Liden, R.C. Panaccio A. Meuser J.D., Hu, J. \& Wayne, S. J, 2014, The Oxford handbook of leadership and organizations, Oxford University Press, Oxford Handbooks Online.

Lu, X., 2014, 'Ethical leadership and organizational citizenship behavior: The mediating roles of cognitive and affective trust', Social Behavior and Personality 42(3), 379-390. https://doi.org/10.2224/sbp.2014.42.3.379

Luthans, F., 2011, Organizational behaviour: An evidence-based approach, 12th edn., McGraw-Hill, New York, NY.

MacKenzie, S.B., Podsakoff, P.M. \& Podsakoff, N.P., 2011, 'Construct measurement and validation procedures in MIS and behavioural research: Integrating new and existing techniques', MIS Quarterly 35(2), 293-334. https://doi.org/10.2307/ 23044045 
Miao, Q., Newman, A., Schwarz, G. \& Xu, L., 2014, 'Servant leadership, trust, and the organisational commitment of public sector employees in China', Public Administration 92(3), 727-743.

Narvaez, D., 2010, 'The emotional foundations of high moral intelligence', New Directions for Child and Adolescent Development 129, 77-94. https://doi.org/ 10.1002/cd.276

Newman, A., Kiazad, K., Miao, Q. \& Cooper, B., 2014, 'Examining the cognitive and affective trust-based mechanisms underlying the relationship between ethical leadership and organisational citizenship: A case of the head leading the heart?', Journal of Business Ethics 123, 113-123. https://doi.org/10.1007/s10551-013-1803-2

Nunnally, J.C., 1978, Psychometric theory, 2nd edn., McGraw-Hill, New York, NY.

Organ, D.W., Podsakoff, P.M. \& Mackenzie, S.B., 2006, Organizational citizenship behavior: Its nature, antecedents, and consequences, Sage, Thousand Oaks, CA.

Pallant, J., 2013, SPSS survival manual: A step by step guide to data analysis using SPSS, 4th edn., McGraw-Hill, Maidenhead.

Preacher, K.J. \& Hayes, A.F., 2004, 'SPSS and SAS procedures for estimating indirect effects in simple mediation models', Behavior Research Methods 36(4), 717-731. https://doi.org/10.3758/BF03206553

Rubin, R.S., Bommer, W.H. \& Bachrach, D.G., 2010, 'Operant leadership and employee citizenship: A question of trust?', The Leadership Quarterly 21(3), 400-408. https://doi.org/10.1016/j.leaqua.2010.03.005

Sendjaya, S. \& Pekerti, A., 2010, 'Servant leadership as antecedent of trust in organizations', Leadership and Organization Development Journal 31(7), 643-663. https://doi.org/10.1108/01437731011079673
Shahzad, A., Rizvi, R.A., Waheed, A., Khan, I., Usman, I., Nazir, N. et al., 2013, 'Linking servant leadership with organisational citizenship behaviour through trust: An embryonic structural modelling approach', European Journal of Social Sciences 39(2), 273-284.

Walumbwa, F.O., Avolio, B., Gardner, W.L., Wernsing, T.S. \& Peterson, S.J., 2008 'Authentic leadership: Development and validation of a theory-based measure', Journal of Management 34(1), 89-126. https://doi.org/10.1177/0149206307 308913

Wickham, M. \& O'Donohue, W., 2012, 'Developing an ethical organization Exploring the role of ethical intelligence', Organization Development Journa 30(2), 9-29.

Williams, L.J. \& McGonagle, A.K., 2016, 'Four research designs and a comprehensive analysis strategy for investigating common method variance with self-report measures using latent variables', Journal of Business and Psychology 31(3), 339-359. https://doi.org/10.1007/s10869-015-9422-9

Wogaman, J.P., 2011, Christian ethics: A historical introduction, 2nd edn., Westminster John Knox Press, Louisville, KY.

Xu, F., Caldwell, C. \& Anderson, V., 2016, 'Moral implications of leadership Transformative insights', International Journal of Business and Social Research 6(3), 76-85. https://doi.org/10.18533/ijbsr.v6i3.940

Zhu, W., Newman, A., Miao, Q. \& Hooke, A., 2013, 'Revisiting the mediating role of trust in transformational leadership effects: Do different types of trust make a difference?', The Leadership Quarterly 24(1), 94-105. https://doi.org/10.1016/j. leaqua.2012.08.004 